\title{
THE COMBINED MECHANISM OF BONE MORPHOGENETIC PROTEIN- AND CALCIUM PHOSPHATE-INDUCED SKELETAL TISSUE FORMATION BY HUMAN PERIOSTEUM DERIVED CELLS
}

\author{
J. Bolander ${ }^{1,2}$, W. Ji ${ }^{1,2}$, L. Geris ${ }^{2,3}$, V. Bloemen ${ }^{1,2,4}$, Y.C. Chai ${ }^{1,2}$, J. Schrooten ${ }^{2,5}$ and F.P. Luyten ${ }^{1,2^{*}}$
}

\begin{abstract}
${ }^{1}$ Tissue Engineering Laboratory, Skeletal Biology and Engineering Research Center, KU Leuven, O\&N 1, Herestraat 49, bus 813, 3000 Leuven, Belgium.

${ }^{2}$ Prometheus, Division of Skeletal Tissue Engineering, KU Leuven, O\&N 1, Herestraat 49, bus 813, 3000 Leuven, Belgium.

${ }^{3}$ Biomechanics Research Unit, University of Liege, Chemin des Chevreuils 1 - BAT 52/3, 4000 Liege 1, Belgium. ${ }^{4} \mathrm{KU}$ Leuven Campus Group T, Andreas Vesaliusstraat 13, 3000 Leuven, Belgium.

${ }^{5}$ Department of Materials Engineering, KU Leuven, Kasteelpark Arenberg 44, bus 2450, 3001 Heverlee, Belgium.
\end{abstract}

\begin{abstract}
When combining osteogenic progenitor cells such as human periosteum derived cells (hPDCs) with osteoconductive biomaterials like calcium phosphate (CaP)-scaffolds, in vivo bone formation can be achieved. This process is dependent on the early activation of Bone morphogenetic protein (BMP)-signalling. However, the bone forming process is slow and routinely only a limited amount of bone and bone marrow is formed. Therefore, we hypothesised that a robust clinically relevant outcome could be achieved by adding more physiological levels of potent BMP-ligands to these cell- and $\mathrm{CaP}$-based constructs.

For this, hPDCs were characterised for their responsiveness to BMP-ligands upon in vitro $2 \mathrm{D}$ stimulation. BMP-2, -4, -6 and -9 robustly induced osteochondrogenic differentiation. Subsequently, these ligands were coated onto clinically approved $\mathrm{CaP}$-scaffolds, BioOss $^{\circledR}$ and CopiOs ${ }^{\circledR}$, followed by hPDC-seeding. Protein lysates and conditioned media were investigated for activation of BMP signalling pathways. Upon in vivo implantation, the most abundant bone formation was found in BMP-2 and BMP-6-coated scaffolds. Implanted cells actively contributed to the newly formed bone. Remnants of cartilage could be observed in BMP-coated CopiOs ${ }^{\circledR}$ constructs.

Computational analysis displayed that the type of BMPligand as well as the CaP-scaffold affects skeletal tissue formation, observed in a qualitative as well as quantitative manner. Furthermore, the in vitro mechanism appears to predict the in vivo outcome. This study presents further evidence for the potential of BMP-technology in the development of clinically relevant cell-based constructs for bone regenerative strategies.
\end{abstract}

Keywords: bone tissue engineering, bone morphogenetic proteins, calcium phosphate, progenitor cell, cell signalling, modelling.

*Address for correspondence:

Frank P. Luyten, MD, PhD

Skeletal Biology and Engineering Research Center

O\&N I Herestraat 49 - box 7003 13, 3000 Leuven, Belgium

Telephone number: +3216372657

Fax number: +3216342543

Email: frank.luyten@uz.kuleuven.ac.be

\section{Introduction}

Over $10 \%$ of annual tibia fractures lead to non-unions, often due to the critical size of the fracture, severely damaged surrounding tissue and/or genetic disorders (Fong et al., 2013). Unfortunately, the gold standard methods to treat non-unions today, autograft or allograft transplants, arouse inevitable limitations such as donor site morbidity and the risk of allogeneic contaminations (Betz, 2002). Subsequently, bone tissue engineering (BTE) has in the last decades emerged as a promising approach of alternative treatments and specifically of cell-based Advanced Therapy Medicinal Products (ATMPs) (Langer and Vacanti, 1993; Ma et al., 2014). The classical elements in this strategy contain osteoprogenitor cells seeded on an osteoconductive 3D material which, when combined with osteoinductive biomolecules, forms a BTE-ATMP.

For a successful outcome, a biomimetic approach such as developmental engineering should be utilised (Lenas et al., 2009a). In view of this, human periosteum derived cells (hPDCs) are particularly of interest, due to their in vivo bone forming capacity and direct contribution in fracture healing (Colnot, 2009; Roberts et al., 2015). In constructs based on hPDC-seeded calcium phosphate (CaP)-scaffolds, $\mathrm{Ca}^{2+}$ was found as an essential determinant for the constructs' bone forming capacity (Roberts et al., 2011). Furthermore, it was shown that activation of the Bone morphogenetic protein (BMP) and Wingless-related (Wnt) signalling was crucial for the osteogenic capacity of the construct (Eyckmans et al., 2010). This is of specific interest since these pathways reflect the key growth factors during limb formation as well as normal fracture healing where they recruit/trigger periosteal cells to aid the fracture healing (Ai-Aql et al., 2008; Barnes et al., 1999; Cho et al., 2002; Yu et al., 2010). Nevertheless, bone formation in these constructs is a slow process and only limited amount of bone and marrow formation have been obtained until today. To improve the bone forming capacity of these $\mathrm{CaP} /$ cell-based constructs further, a potential biomimetic strategy could be to coat the scaffolds with osteoinductive factors such as BMPs prior to cell seeding.

In the clinical setting, BMP-2 and BMP-7 have been approved, but due to the design of these medicinal products, supra-physiological levels of BMPs are required, leading to side effects (Glassman et al., 2007; Graham et al., 2014; Pobloth et al., 2015; Tiedemann et al., 2001; Varga and Wrana, 2005; White et al., 2007; Wu and Hill, 2009). When 
inducing physiological cellular responses, BMP-ligands activate intracellular signalling by binding to their cognate transmembrane receptors. The active receptor complex resides on one of the type1 receptors: Activin Receptorlike Kinase (ALK)1, ALK2, ALK3 or ALK6 and one of the type 2 receptors: BMP-receptor type 2 (BMPR2), Activin type 2 receptor (ACVR2)a or ACVR2b (Shimasaki et al., 2004). BMP ligands bind to their receptors with different affinities depending on cell type, cellular state and environment, whereas the oligomerisation mechanism determines downstream signalling activation (Gilboa et al., 2000; Hartung et al., 2006; Nohe et al., 2002). Even though research progressively unravels the complex intracellular system of BMP-signalling, limited information is available regarding the biological performance of the different BMPs on clinically relevant progenitor cells such as hPDCs. In addition, in the perspective of BTE-strategies for clinical translation, it is of relevance to know how a 3D CaP-environment affects the cellular response to more physiological levels of BMP-ligands and how this is reflected in the in vivo situation.

In view of this, the current study aimed to evaluate the biological performance of ATMPs constituted of BMPs and CaP-scaffolds as osteoinductive and -conductive raw materials and hPDCs as osteoprogenitor cells. Initially, hPDCs were characterised in terms of their responsiveness to different BMP-ligands. The most potent members were selected for coating onto two clinically used CaP scaffolds: BioOss $^{\circledR}$ and CopiOs ${ }^{\circledR}$, with previously reported limited and no bone forming capacity in combination with hPDCS, respectively (Roberts et al., 2011). Activated signalling pathways were analysed in vitro and the skeletal tissue forming capacity of the cell-based BMP-CaP constructs was investigated in vivo. As a last step, computational analysis was used to deduce key factors in the empirical data set.

\section{Materials and Methods}

\section{Characterisation of hPDCs}

Expansion of human periosteum-derived cells ( $h P D C s$ ) Isolation and in vitro expansion of hPDCs were carried out as previously described (De Bari et al., 2001). Expanded cells from six different donors (age 14.9 \pm 2.1 ) were pooled as a representative sample and in vitro expanded in growth medium (GM) consisting of high-glucose Dulbecco's modified medium (DMEM, Invitrogen, Merelbeke, BE) supplemented with $10 \%$ foetal bovine serum (FBS) (Gibco, Merelbeke, BE), sodium pyruvate and antibioticsantimycotics solution (Invitrogen). Upon confluence, hPDCs were trypsin-released (1 mM EDTA; Invitrogen) and re-plated with a seeding density of $5000 \mathrm{cells} / \mathrm{cm}^{2}$ and used accordingly at passage 5 . The ethical committee for human medical research (KU Leuven) approved all procedures, and the patient informed consents were obtained.

\section{Mesenchymal stem cell markers and hPDCs}

Prior to the in vitro evaluation, flow cytometry was performed to characterise the expression of mesenchymal stem cell (MSC) markers on hPDCs by using a human MSC phenotyping kit (130-095-198, Miltenyi Biotec, Leiden, $\mathrm{NL}$ ). The extracellular staining was performed according to the manufacturer's instruction. In brief, the cell suspension was mixed with MSC Phenotyping Cocktail and incubated in dark at $4{ }^{\circ} \mathrm{C}$. Cells were washed and analysed using BD FACS Canto ${ }^{\mathrm{TM}}$ cell analyser (BD Biosciences, San Jose, USA) with FlowJo V10 software.

\section{BMP receptor expression}

Expression of BMP type 1 and type 2 receptors was investigated by mRNA transcript analysis. Total RNA from expanded hPDCs was extracted by lysing cells in RLT buffer supplemented with $\beta$-mercaptoethanol. Further RNA extraction was performed using the RNeasy kit (Qiagen, Venlo, NL) according to the manufacturer's instructions. Complementary DNA (cDNA) was obtained by reverse transcription of total RNA with Oligo (dT)20 as primer (Superscript III; Invitrogen). Quantitative PCR was performed in duplicates on a Rotor-Gene 6000 system (Corbett, Westburg, Leusden, NL) as previously described (Roberts et al., 2011). Relative gene expression levels were calculated using the $2^{-\Delta \mathrm{CT}}$ or $2^{-\Delta \Delta \mathrm{CT}}$ method by normalising to the housekeeping gene hypoxanthine phosphoribosyltransferase 1 (HPRT1) and non-stimulated control. For primer sequences see table 1. On protein level, expression of BMP type 1 and type 2 receptors

Table 1. Primer sequences.

\begin{tabular}{|c|c|c|}
\hline Gene & Forward sequence & Reverse sequence \\
\hline SOX9 & TGGAGACTTCTGAACGAGAGC & CGTTCTTCACCCACTTCCTC \\
\hline$A C A N$ & GTCTCACTGCCCAACTAC & GGAACACGATGCCTTTCAC \\
\hline$R U N X 2$ & CGCATTCCTCATCCCAGTAT & GCCTGGGGTCTGTAATCTGA \\
\hline OSX & AGTGACCTTTCAGCCTCCAA & GGGAAAAGGGAGGGTAATCA \\
\hline$D L X 5$ & CAGCCAAAGCTTATGCCGAC & CGGTCACTTCTTTCTCTGGCT \\
\hline ID1 & GGCTGTTACTCACGCCTCAAG & CCAACTGAAGGTCCCTGATGTAG \\
\hline ALK1 & ATCTGAGCAGGGCGACAC & ACTCCCTGTGGTGCAGTCA \\
\hline$A L K 2$ & ATGTGACCAAGAGCCTGCAT & CGCAGGAGAGACCTTCACAC \\
\hline$A L K 3$ & CAGGGCACTGTCCAGATGAT & AGCTGGGCTTTTGGAGAATC \\
\hline ALK6 & ATGACTCTGGGTTGCCTGTG & TCAATGGAGGCAGTGTAGGG \\
\hline BMPR2 & GGTTGGAAACCATCCCACTT & TGGTCCCAACAGTCTTCGAT \\
\hline$A C V R 2 A$ & CCGGAGATGGAAGTCACACAGCCC & TGGGGGTGGTCCTGGGTCTTGA \\
\hline$A C V R 2 B$ & GCTGCAGACGGACCCGTGGA & GGCCAGGCCCGGGTGTTTCA \\
\hline
\end{tabular}


was detected by immunohistochemistry (IHC). A human prostate cancer cell line (PC3) was used as a positive control. Cells cultured on 4-well chamber slides (Thermo Scientific $^{\mathrm{TM}}$ Nunc $^{\mathrm{TM}}$ Lab-Tek $^{\mathrm{TM}}$, Breda, NL) were fixed and permeabilised (PBS containing $0.5 \%$ Triton-X and $10 \%$ FBS) before antibody incubation. Next, cells were incubated overnight at $4{ }^{\circ} \mathrm{C}$ with human specific antibody ALK2 (AF637, R\&D Systems), ALK3 (NBP2-37421, Novus Biologicals, Abingdon, UK), ALK6 (Mab5051, R\&D Systems, Abington, UK) or BMPR2 (AF811, R\&D Systems). As isotype controls, cells were stained with normal goat IgG (AB-108-C, R\&D Systems), mouse IgG2B (mab0041, R\&D Systems) and mouse IgG1 (ab18447, Abcam, Cambridge, UK). Subsequently, cells were stained with nucleus stain 4'-6-diamidino-2-phenylindole (DAPI) dye (1:2000) and donkey anti-goat IgG, Alexa Fluor $^{\circledR} 488$ conjugate $(1: 200$, A21432, Life Technologies, Erembodegem, BE) or donkey anti-mouse IgG Alexa Fluor $^{\circledR} 488$ conjugate (1:200, A21202, Life Technologies). Samples were mounted in Mowiol (Merck, Darmstadt, DE) for fluorescent microscopic analysis (Leica, Diegem, BE and Spot Imaging Solutions ${ }^{\mathrm{TM}}$, Sterling Heights, USA).

\section{Response of 2D cultured hPDCs to BMP-stimulation}

In vitro expanded cells were seeded in monolayer cultures at a density of 10,000 cells $/ \mathrm{cm}^{2}$ and left overnight for attachment. Monolayers were washed in PBS followed by synchronisation for $16 \mathrm{~h}$ in GM containing $0.1 \%$ FBS. Next, cells were stimulated with GM supplemented with $100 \mathrm{ng} / \mathrm{mL}$ of vehicle (PBS, in order to dilute stock solutions), BMP-2, BMP-4, BMP-6, BMP-7, BMP-9 or Growth differentiation factor 5 (GDF-5) (Peprotech, London, UK) for $6 \mathrm{~d}$. Following stimulation, monolayers were imaged by bright field microscopy (Zeiss, Zaventem, BE) followed by RNA isolation. Subsequent mRNA analysis was performed as described in the section headed $B M P$ receptor expression. Gene expression analysis for chondrogenic markers; sex determining region Y-box 9 (SOX9) and aggrecan $(A C A N)$, osteogenic markers; Runt-related transcription factor 2 (RUNX2), osterix $(O S X)$ and osteocalcin $(O C N)$ together with activated BMP-signalling; inhibitor of differentiation 1 (IDI) and distal-less homeobox 5 (DLX5) was performed. Primer sequences are defined in Table 1.

\section{Characterisation of 3D CaP-environment \\ Biomaterial preparation}

Two clinical grade CaP-based scaffolds with known bone forming capacity in combination with hPDCs, i.e.: limited bone formation: BioOss ${ }^{\circledR}$ (Geistlich, Princeton, US); and no bone formation: Copios ${ }^{\circledR}$ (Zimmer, Wemmel, $\mathrm{BE}$ ) were selected based on previous work (Roberts et al., 2011). CopiOs ${ }^{\circledR}$ contains synthetic CaP-granules embedded in bovine collagen and BioOss ${ }^{\circledR}$ contains bovine $\mathrm{CaP}$-granules embedded in porcine collagen. From each material cylindrical $(3 \mathrm{~mm}$ diameter and 3 or $5 \mathrm{~mm}$ in height for BioOss ${ }^{\circledR}$ and $\mathrm{CopiOs}^{\circledR}$, respectively) scaffolds were punched out.

\section{$\mathrm{Ca}^{2+}$ release measurements from the biomaterials}

The release kinetics of $\mathrm{Ca}^{2+}$ from the biomaterials were analysed by Inductively Coupled Plasma-Atomic Emission Spectrometry (ICP-AES). Briefly, scaffolds were submerged in $\mathrm{Ca}^{2+}$-free $\mathrm{PBS}$ and rotated at $37^{\circ} \mathrm{C}$. Samples were collected to measure the release kinetics after 24, 74 and $144 \mathrm{~h}$. Standards were used to assess $\mathrm{Ca}^{2+}$ concentration and blank medium was used as baseline. Subsequent analyses were performed by ICP-AES, using a Varian, Liberty Series II.

\section{BMP-coating and cell seeding of biomaterials}

Five groups of scaffolds $(n=7)$ loaded with the BMPligands were set up for cellular response evaluation. The doses and resources of BMPs are listed in Table 2. Each scaffold was coated with $50 \mathrm{ng} / \mathrm{mm}^{3}$ scaffold of BMP ligand or vehicle and left for adsorption for $1 \mathrm{~h}$ at $37^{\circ} \mathrm{C}$. Subsequently, 50,000 hPDCs $/ \mathrm{mm}^{3}$ scaffold were dropseeded onto coated scaffolds. Constructs were incubated for $24 \mathrm{~h}$ at $37{ }^{\circ} \mathrm{C}$ and $5 \% \mathrm{CO}_{2}$ to allow cell attachment. Next, medium was collected for analysis of BMP-release from the scaffold together with lactate and glucose measurements. Constructs were used for further protein phosphorylation analysis $(n=3)$ and in vivo implantation $(n=4)$.

\section{BMP-2 release from biomaterials}

The materials' ability to retain coated growth factors was analysed by a human BMP-2 enzyme linked immunosorbent assay (ELISA) development kit (Peprotech). Conditioned

Table 2. Conditions for 3D constructs.

\begin{tabular}{|c|c|c|c|c|c|}
\hline Group & Scaffold & Scaffold manufacturer & BMP-coating & Dose & BMP-resource \\
\hline Control BioOss ${ }^{\circledR}$ & BioOss $\AA$ & Geistlich & Vehicle coated & ND & ND \\
\hline Control CopiOs $\AA$ & CopiOs $\AA$ & Zimmer & Vehicle coated & ND & ND \\
\hline BioOss ${ }^{\circledR}-$ BMP-2 & BioOss $\AA$ & Geistlich & BMP-2 & $50 \mathrm{ng} / \mathrm{mm}^{3}$ & Medtronic \\
\hline CopiOs $®-B M P-2$ & CopiOs $\AA$ & Zimmer & BMP-2 & $50 \mathrm{ng} / \mathrm{mm}^{3}$ & Medtronic \\
\hline BioOss ${ }^{\circledR}-$ BMP-4 & BioOss $\AA$ & Geistlich & BMP-4 & $50 \mathrm{ng} / \mathrm{mm}^{3}$ & PeproTech \\
\hline CopiOs $®-B M P-4$ & CopiOs ${ }^{\circledR}$ & Zimmer & BMP-4 & $50 \mathrm{ng} / \mathrm{mm}^{3}$ & PeproTech \\
\hline BioOss $(-$ BMP-6 & BioOss $\AA$ & Geistlich & BMP-6 & $50 \mathrm{ng} / \mathrm{mm}^{3}$ & Genera research \\
\hline CopiOs $®-B M P-6$ & CopiOs ${ }^{\circledR}$ & Zimmer & BMP-6 & $50 \mathrm{ng} / \mathrm{mm}^{3}$ & Genera research \\
\hline BioOss ${ }^{\circledR}$-BMP-9 & BioOss $\AA$ & Geistlich & BMP-9 & $50 \mathrm{ng} / \mathrm{mm}^{3}$ & PeproTech \\
\hline CopiOs $®-B M P-9$ & CopiOs $\AA$ & Zimmer & BMP-9 & $50 \mathrm{ng} / \mathrm{mm}^{3}$ & PeproTech \\
\hline
\end{tabular}


media from BMP-2 coated scaffolds, non-seeded or seeded with hPDCS, were collected after $24 \mathrm{~h}$. The ELISA was performed according to the manufacturer's instructions.

\section{Lactate and glucose measurements}

The lactate and glucose concentrations in the medium were measured by two clinical diagnosis test strips; lactate ProTM test strip (ARKRAY, Europe B.V, NL) and Contour ${ }^{\circledR}$ blood glucose test strips (Bayer Consumer Care AG, $\mathrm{CH}$ ). The measurements were performed according to manufacturer's instructions. In brief, samples were loaded on the strip and immediately read by a Contour ${ }^{\mathbb{R}}$ meter (Bayer Consumer Care AG). Each sample was measured twice to minimise technical error. Blank medium was measured as control to calculate lactate production and glucose consumption. Thereafter, the ratio of lactate production to glucose consumption per cell was calculated to compare the metabolic activity of the cells upon seeding in different groups.

\section{Downstream pathway activation by Western blot}

Cell-seeded 3D materials were homogenised in Cell Extraction Buffer (Thermo Scientific) containing 0.3 M Phenylmethanesulphonyl fluoride and Protease Inhibition Cocktail (Sigma-Aldrich, Bornem, BE). Protein concentration was determined using the Pierce BCA Protein Assay Kit (Thermo Scientific) according to manufacturer's instructions. Equal quantities of protein were loaded on NuPAGE 4-12\% Bis-Tris gels (Invitrogen) and electrophoresed to separate proteins according to size. These proteins were subsequently transferred to a Polyvinylidene fluoride membrane by wet transfer for further analysis. Phosphorylation of Smad1/5/8, p38, ERK1/2 and MEK1/2 was investigated, representing canonical Smad-dependent as well as non-canonical Smadindependent BMP-signalling. Primary antibodies were diluted according to the manufacturer's instructions: rabbit monoclonal Phospho-p44/42 MAPK (Erk1/2) (Thr202/ Tyr204) (197G2), rabbit p44/42 MAPK (Erk1/2), rabbit monoclonal Phospho-p38 MAPK (Thr180/Tyr182) (12F8), rabbit p38 MAPK, rabbit polyclonal Phospho-Smad1 (Ser463/465)/Smad5 (Ser463/465)/Smad8 (Ser426/428) (Cell Signalling Technology- BIOKÉ, Leiden, NL). Glyceraldehyde-3-phosphate dehydrogenase (GAPDH) mouse monoclonal (Abcam) was used to assess equal loading of proteins. HRP-conjugated secondary antibodies were used at dilution of 1:2000 (Jackson, Pennsylvania, US) and images were developed by a LAS3000 Imaging System (FUJI) following the application of SuperSignal ${ }^{\mathbb{R}}$ West Femto reagent (Thermo Scientific, Illnois, US). Densitometry analysis was performed using Biorad Quantity One software.

\section{In vivo osteogenesis}

Constructs $(n=4)$ (prepared as described in the section headed BMP-coating and cell seeding of biomaterials) were implanted subcutaneously in the cervical region of $\mathrm{NMRI}^{\text {nu/nu }}$ mice (Janvier, Genest Saint Isle, FR). For in vivo bone formation, explants were harvested 5 weeks post implantation, fixed in $4 \%$ paraformaldehyde and stored in PBS until further analysis. For 3D quantification and qualitative analysis, explants were scanned by nanofocus $\mathrm{X}$-ray computed tomography (nanoCT) followed by processing for histology and immunohistochemistry (IHC). All animal procedures were approved by the local ethical committee for Animal Research (KU Leuven). The animals were housed according to the guidelines of the Animalium Leuven (KU Leuven).

\section{Quantification of de novo formed bone by nanoCT}

For 3D analysis of in vivo formed bone, explants were analysed using the Phoenix NanoTom S nanoCT system, (GE Measurement and Control Solutions, Wunstorf, DE) with a $180 \mathrm{kV} / 15 \mathrm{~W}$ high-performance nanofocus X-ray tube as previously described (Kerckhofs et al., 2013). Briefly, the system was equipped with a tungsten target and was operated at a voltage of $60 \mathrm{kV}$ and a current of $200 \mu \mathrm{A}$. A $1 \mathrm{~mm}$ aluminium filter was used to reduce beam hardening. The exposure time was $500 \mathrm{~ms}$ and a frame averaging of 1 and image skip of 0 were applied. CTAn software was used for 3D quantification (Bruker micro-CT, Kontich, BE), which employed a three-level automatic Otsu segmentation algorithm on the individual 2D slice where de novo formed bone and the CaP-grains could be segmented from the background. As a result, grey-scale images with distinct grey scale values for the bone, the $\mathrm{CaP}$-grains and the background were generated for the different subsets. Percentage of bone was calculated with respect to the total explant volume.

Qualitative analysis of constructs in vivo performance After nanoCT scanning, the samples were decalcified in 0.5 M EDTA/PBS for 2 weeks, paraffin embedded and processed for qualitative assessment.

\section{Histology}

To analyse bone and bone marrow formation, haematoxylin and eosin (H\&E) staining was performed. Briefly, paraffin sections were deparaffinised and subsequently immersed in haematoxylin (Sigma-Aldrich), rinsed in $\mathrm{H}_{2} \mathrm{O}$ followed by immersion in eosin (Klinipath, Duiven, NL). Finally, the sections were rinsed in $\mathrm{H}_{2} \mathrm{O}$, dried in ethanol, cleared in Histoclear and mounted in PerTex mounting medium (CellPath, Wales, UK). Presence of cartilaginous matrix was investigated by toluidine blue staining. Sections were deparaffinised and subsequently immersed in $1 \%$ toluidine blue (Merck). Next, sections were rinsed twice with isopropanol, cleared in xylene and mounted in PerTex. Bone remodelling was investigated by tartrate resistant acid phosphatase (TRAP) staining, performed to localise the presence of osteoclasts. Sections were deparaffinised and rehydrated through alcohols to PBS. Subsequently, sections were incubated with TRAP buffer containing $0.1 \mathrm{M}$ acetate buffer, $0.3 \mathrm{M}$ sodium tartrate and $1 \%$ Triton X-100. The sections were then incubated in TRAP stain containing naphthol AS-MX phosphate (Sigma-Aldrich) and fast red violet LB (Sigma-Aldrich) in TRAP buffer at $37^{\circ} \mathrm{C}$. Each sample was counterstained in haematoxylin for $10 \mathrm{~s}$ and mounted with aqueous mounting medium. 
a
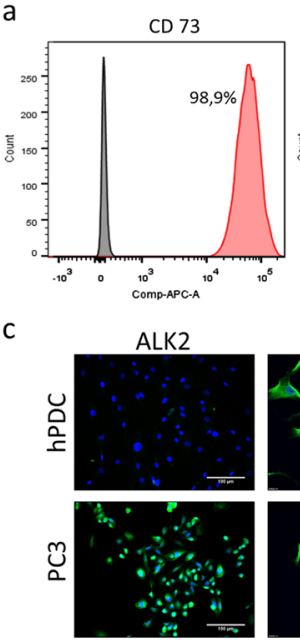
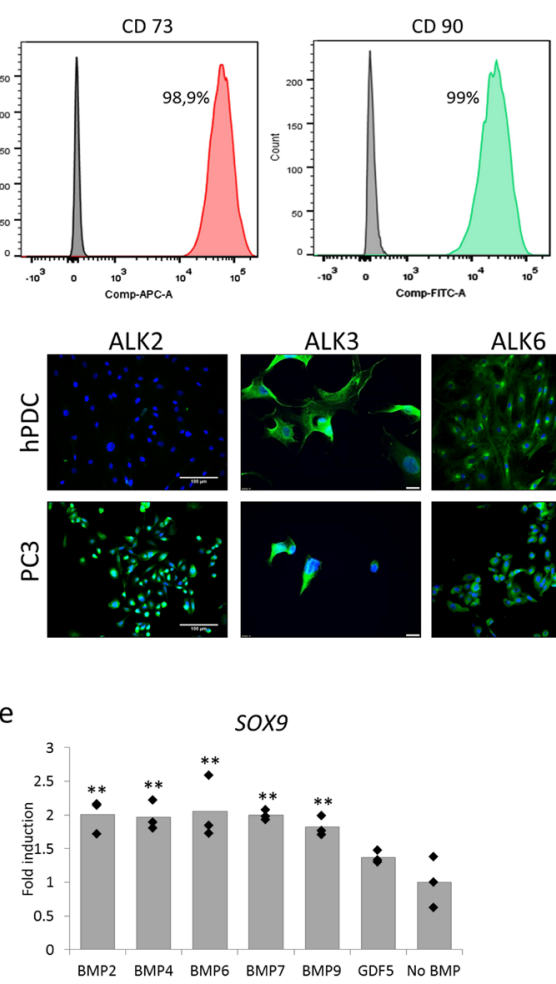

$f$

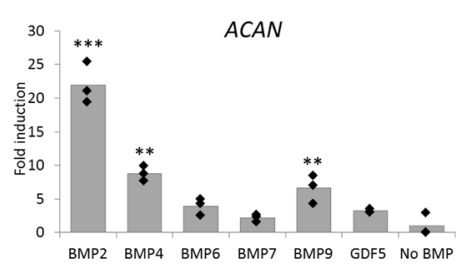

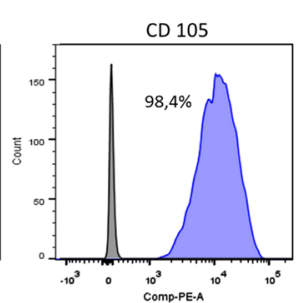

BMPR2
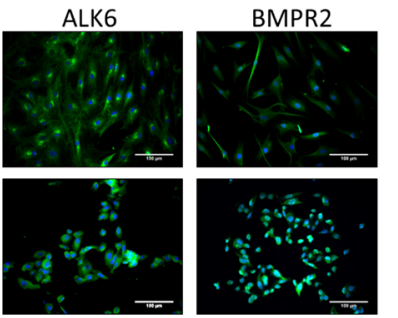

b

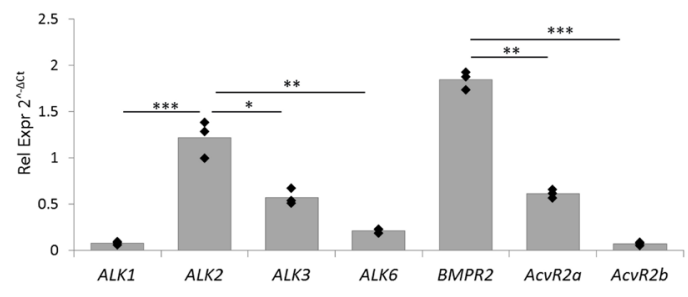

d

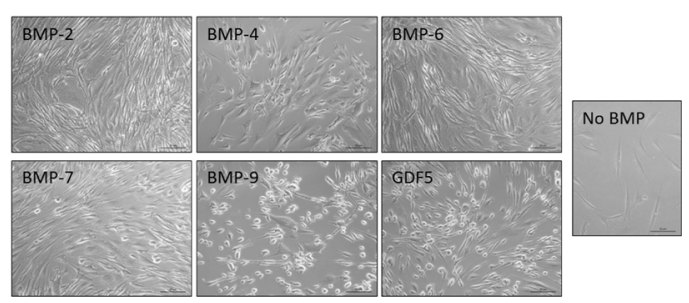

g

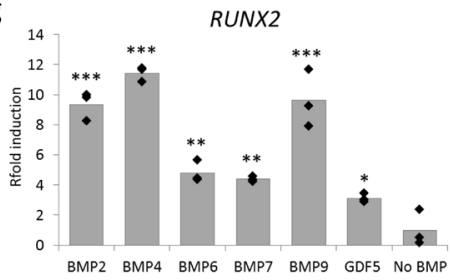

h

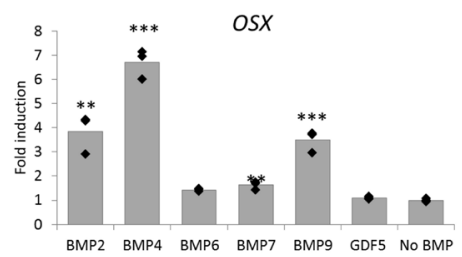

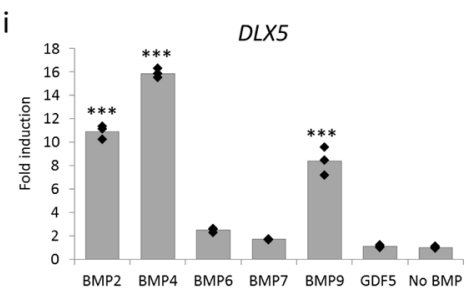

j

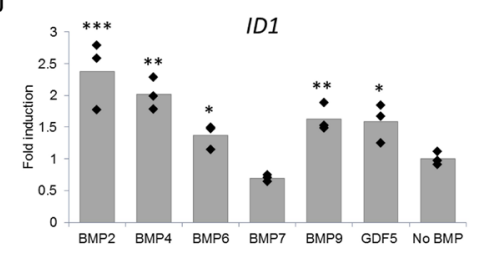

Fig. 1. hPDC characterisation and BMP-responsiveness. FACS analysis displayed 2D expanded hPDCs $93 \%$ positive for MSC markers CD73, CD90 and CD105 (a). mRNA transcript analysis in 2D expanded hPDCs confirmed expression of BMP type 1 and type 2 receptors (b). Expression of BMP-receptors on protein level (green) with DAPI as nuclear stain (blue) in hPDCs (c). Functional antibody was confirmed in a prostate cancer cell line (PC3) (c). Monolayer cultures of hPDCs were stimulated with different BMP-ligands for $6 \mathrm{~d}$. Bright field images displayed morphological differences between cells stimulated with different BMP-ligands (d). mRNA transcript analysis after $6 \mathrm{~d}$ of stimulation displayed varied elevated expression of chondrogenic (e-f), osteogenic (g-h) and BMP-signalling (i-j) markers. Statistical significance by student $t$-test to untreated cells: ${ }^{*} p<0.05,{ }^{* *} p<0.01,{ }^{* * *} p<0.01(n=3)$. Unlabelled scale bar: $20 \mu \mathrm{m}$.

Immunohistochemistry

IHC for human OCN was performed on deparaffinised sections which were quenched in $3 \% \mathrm{H}_{2} \mathrm{O}_{2}$ followed by antigen retrieval in sodium citrate, $10 \mathrm{mM}, \mathrm{pH}$, at $98^{\circ} \mathrm{C}$. Sections were then incubated in primary antibody for $24 \mathrm{~h}$ at $4{ }^{\circ} \mathrm{C}$ using a primary anti-OCN guinea pig antibody at a 1:1000 dilution (a generous gift from Dr. E. Van Herck, Legendo, KU Leuven) which does not cross-react with mouse OCN (De Bari et al., 2006). A HRP-conjugated anti guinea pig secondary antibody was used at a dilution of 1:500 (Jackson) and 3,3'-diaminobenzidine (DAB, SigmaAldrich) were used as a chromogenic substrate.

\section{Histomorphometry}

For semi-quantitative analysis, stained tissue sections were imaged for an overview or at four defined locations per section and used as a representative. ImageJ software was used for bone marrow quantification and scanned images from 3 sections per explant were utilised for an average value. The colour threshold was adjusted to depict the areas that display the positive areas by defining minimum and maximum values for each colour and an in-house developed MatLab code was used to quantify the positive area normalised to the total area. For positive OCN staining, images were blindly analysed and scored.

\section{Statistical analysis}

Data are expressed as individual data points with bars representing the average value. Statistical significance was determined using a non-paired unequal variance student $t$-test to compare between independent groups. Statistical significance is indicated on all graphs as follows; statistical significance to untreated control: \#: $p<0.05$, \#\#: $p<0.01$, \#\#\#: $p<0.001$; between conditions: $*: p<0.05$, $* *: p<0.01, * * *: p<0.001(n=3$ for in vitro data and $n=4$ for in vivo data). Principal component analysis (PCA) and hierarchical clustering using Ward's method were performed in JMP ${ }^{\circledR} 10$ (SAS Institute Inc., Cary, NC). 


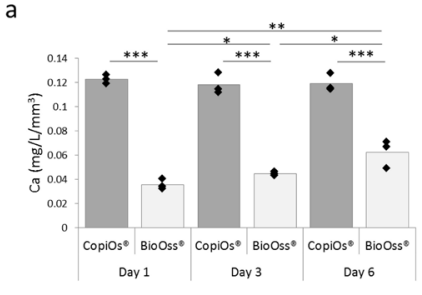

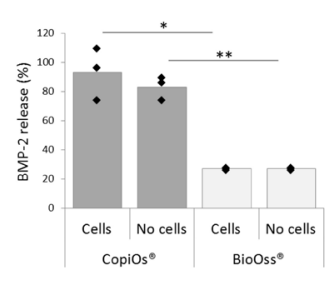

c $\quad 3 .+* * *$

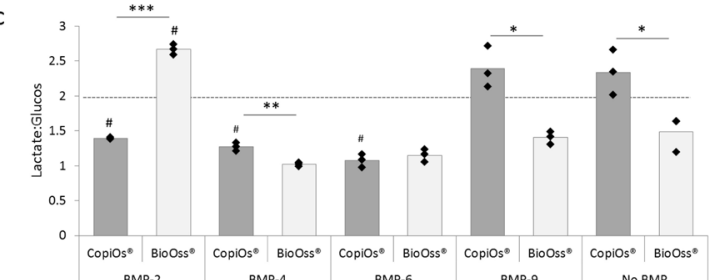

BмP-2
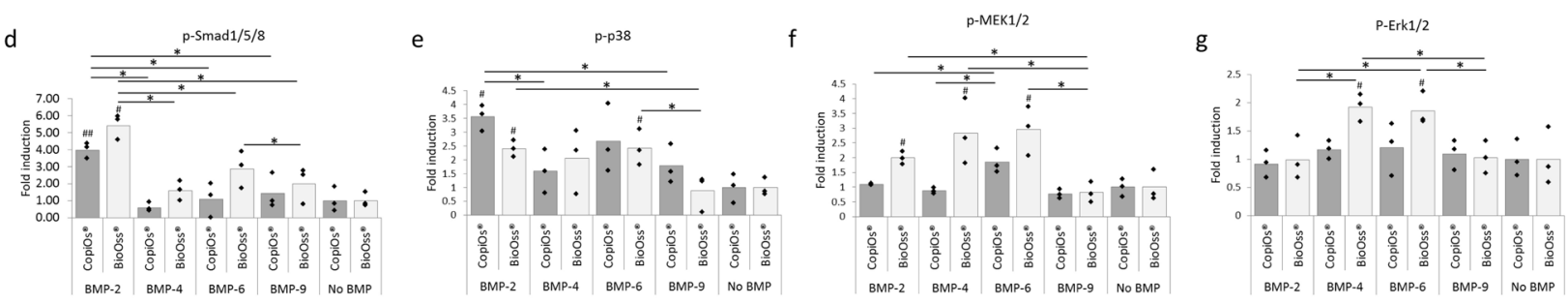

Fig. 2. $\mathrm{Ca}^{2+}$ and BMP-2 release from CaP scaffolds and cellular response. To characterise material properties of the BioOss $^{\circledR}$ and CopiOs ${ }^{\circledR}$ scaffolds, $\mathrm{Ca}^{2+}$ release was measured for $6 \mathrm{~d}$ (a). Scaffolds were then coated with the most potent BMP-ligands in inducing 2D differentiation and subsequently cell seeded. BMP-2 release was measured in BMP-2 coated scaffolds seeded with or without cells (b). Cell metabolism was investigated through Lactate: Glucose production and consumption $24 \mathrm{~h}$ post cell seeding $(\mathbf{c})$. At the same time point, protein phosphorylation for downstream BMP-signalling was investigated through Western blot for the canonical BMP-pathway; Smad1/5/8 (d) and the noncanonical MAPK pathways; p38 (e), MEK1/2 (f) and Erk1/2 (g). Statistical significance by student $t$-test, $n=3$, to: uncoated scaffolds: $\# p<0.05, \# \#<0.01, \# \# \# p<0.01$, between conditions: ${ }^{*} p<0.05, * * p<0.01, * * * p<0.01$.

\section{Results}

\section{Characterisation of hPDCs' responsiveness to BMPs}

In vitro $2 \mathrm{D}$ expanded hPDCs were analysed for their MSC phenotype by flow cytometry and displayed $98.9 \%$ positivity for CD73, CD90 and CD105 whereas $93 \%$ were detected negative for haematopoietic markers CD14, CD20, CD34 and CD45, Fig. 1a. Next, mRNA transcripts for BMP type1 and type 2 receptors (ALK1, ALK2, ALK3 and $A L K 6$ as well as $B M P R 2, A C V R 2 a$ and $A C V R 2 b)$ were detected, Fig. 1b. On protein level, expression of ALK3, ALK6 and BMPR2 was confirmed but not ALK2, Fig. 1c. Functional antibody was confirmed in a prostate cancer cell line (PC3). After $6 \mathrm{~d}$ of $2 \mathrm{D}$ stimulation in the presence of BMP-2, -4, -6, -7, -9 or GDF5, bright field images displayed differences in cell morphologies upon incubation with the different ligands, Fig. 1d. Culture in the presence of BMP-2, -6 and -7 induced a more confluent and elongated culture whereas a BMP-4, -9 and GDF5 treatment resulted in a round cell shape. The early chondrogenic marker $S O X 9$ displayed a 2-fold upregulation in hPDCs when stimulated with BMP-2, BMP-4, BMP-6, BMP-7 and BMP-9 as compared to non-stimulated cells, Fig. 1e. $A C A N$, the main proteoglycan in cartilage matrix, hence a marker for chondrogenic differentiation, displayed a 20-, 10- and 5-fold elevated expression upon BMP-2, BMP-4 and BMP-9 stimulation, respectively, Fig. 1f. Analysis of the early osteogenic marker RUNX2 demonstrated an increased expression in all BMP-stimulated cells, Fig. $1 \mathrm{~g}$. A 10-fold elevation was observed by BMP-2, BMP-4 and BMP-9. Elevated $O S X$ expression was induced by BMP2, BMP-4, BMP-7 and BMP-9, Fig. 1h. To see whether the enhanced differentiation was associated with activated BMP-signalling, expression of the BMP-target gene ID1 and the transcriptional regulator $D L X 5$ were investigated.
In parallel to enhanced chondrogenesis and osteogenesis, a 10- and 2-fold upregulation of DLX5 and ID1 expression were detected when cultured in the presence of BMP-2, BMP-4 and BMP-9, Fig. 1i and 1j, respectively.

\section{$\mathrm{Ca}^{2+}$ and BMP-2 release from $\mathrm{BiOOss}^{\circledR}$ and $\mathrm{CopiOs}^{\circledR}$ scaffolds}

As a first step, $\mathrm{Ca}^{2+}$-release was measured from the scaffolds during a 6-day period. A 3-fold higher burst release within $24 \mathrm{~h}$ was observed in the CopiOs ${ }^{\circledR}$ scaffold as compared to BioOss $^{\circledR}$, Fig. 2a. The high release level of CopiOs ${ }^{\circledR}$ was maintained during the investigated period. However, in the BioOss ${ }^{\circledR}$ scaffold the level increased significantly on day 3 and 6 as compared to the first $24 \mathrm{~h}$. Consistent with $\mathrm{Ca}^{2+}$ release, BMP-2 coated CopiOs ${ }^{\circledR}$ displayed a 3-fold higher burst release of BMP-2 after $24 \mathrm{~h}$ as compared to BioOss ${ }^{\circledR}$ scaffold, Fig. 2b. Cell seeding did not affect the BMP-2 release.

\section{In vitro cell metabolism on CaP scaffolds}

Based on gene expression analysis on 2D differentiated cells, BMP-2, BMP-4, BMP-6 and BMP-9 were further selected for coating of BioOss ${ }^{\circledR}$ and CopiOs ${ }^{\circledR}$ followed by cell seeding for 3D stimulation. Cell metabolism was investigated by measuring the ratio of lactate production to glucose consumption in conditioned media, Fig. 2c. Proliferating cells mainly use an aerobic fermentation process, where one glucose molecule results in two molecules of lactate. Hence, a ratio that differs from two may indicate that cells have adapted the metabolic pathway due to initiation of differentiation (e.g. oxidative phosphorylation (osteogenic differentiation) or altered anaerobic glycolysis (chondrogenic differentiation)). Cells seeded on non- or BMP-9 coated CopiOs ${ }^{\circledR}$ scaffolds and BMP-2 coated BioOss ${ }^{\circledR}$ displayed a ratio of 2 or above. 
a

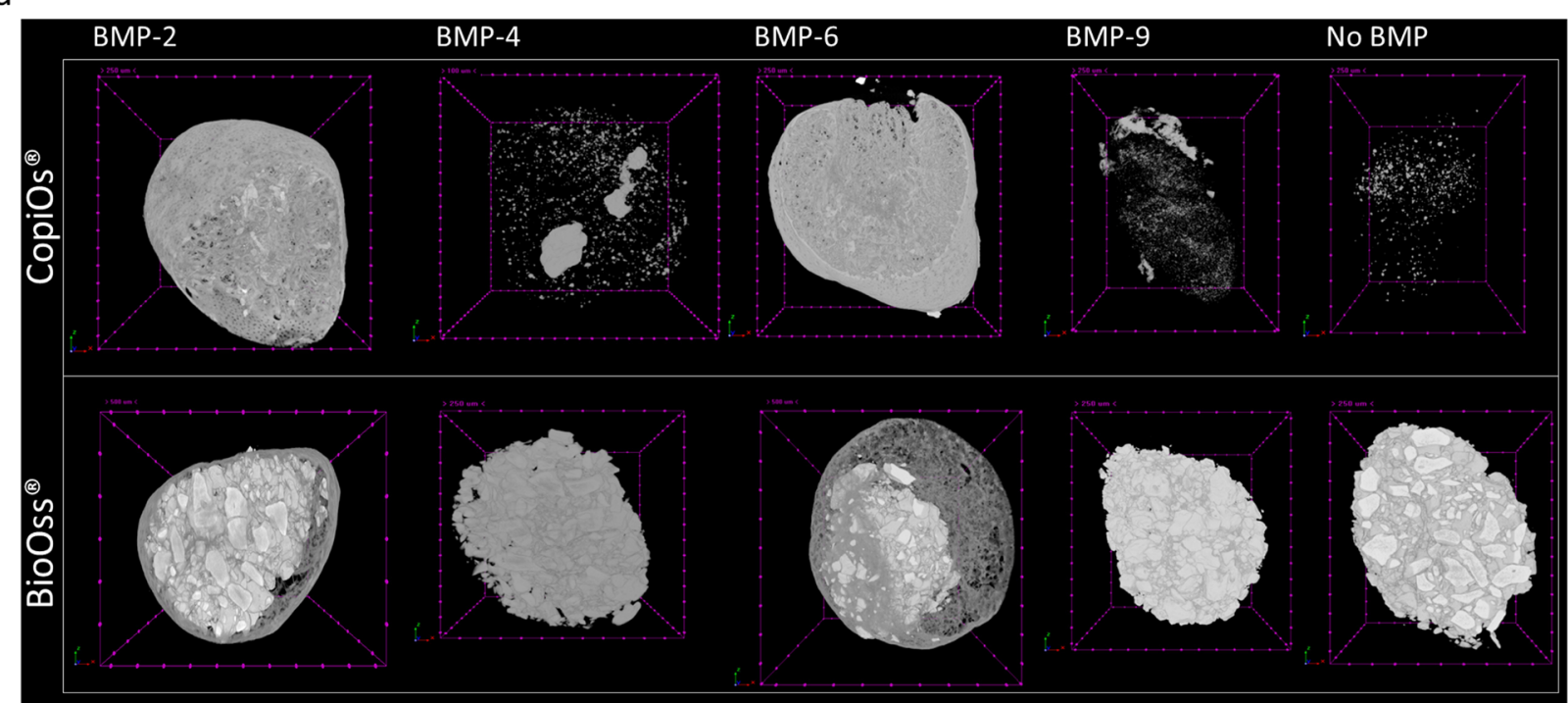

b

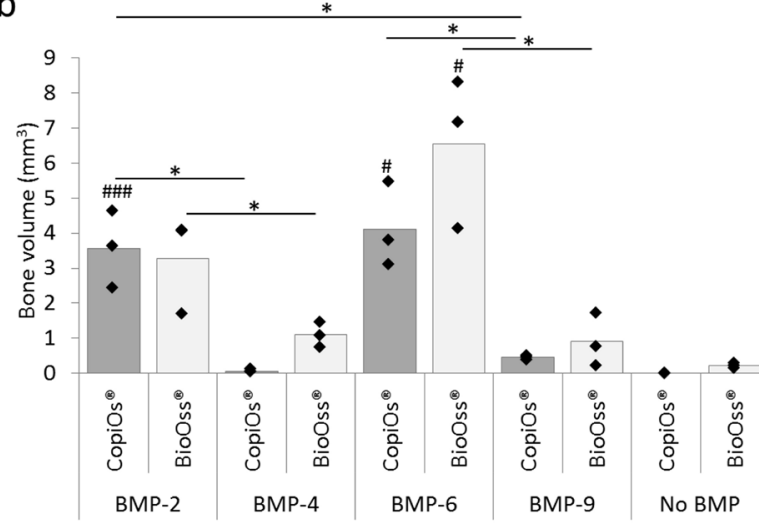

C

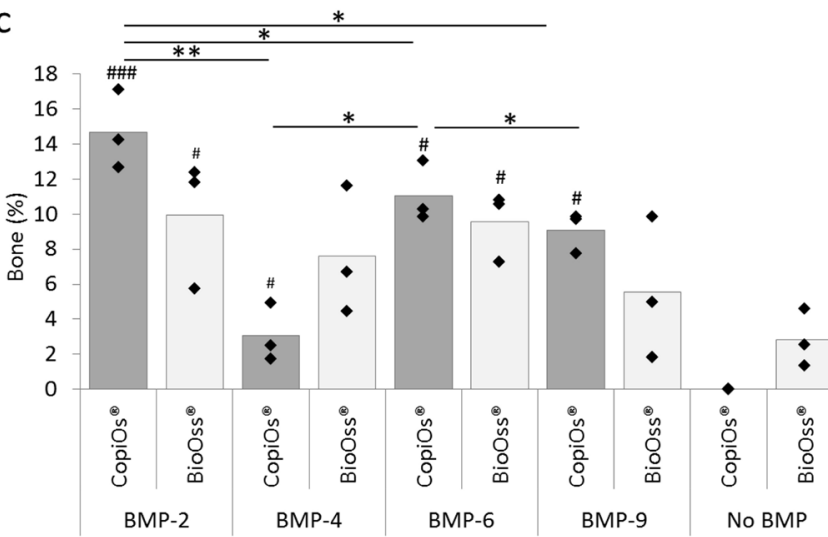

Fig. 3. Quantification of BMP-induced bone formation. BMP-coated and cell seeded BioOss ${ }^{\circledR}$ and CopiOs ${ }^{\circledR}$ scaffolds were subcutaneously implanted in $\mathrm{NMRI}^{\mathrm{nu} / \mathrm{nu}}$ mice for 5 weeks. Explants were scanned by nanoCT for 3D visualisation (a) and total bone quantification (b). Since total explant volume varied between the different constructs, total bone percentage was calculated normalised to explant volume (c). Statistical significance by student $t$-test, $n=3$, to: uncoated scaffolds: $\# p<0.05, \# \# p<0.01$, \#\#\#p<0.01, between conditions: ${ }^{*} p<0.05, * * p<0.01, * * * p<0.01$.

Significantly lower ratios were seen in $\mathrm{CopiOs}^{\circledR}$ coated with BMP-2, BMP-4 and BMP-6, as compared to noncoated scaffold.

\section{In vitro BMP-pathway activation on CaP scaffolds}

Next, protein lysates were prepared from the constructs $24 \mathrm{~h}$ post cell seeding for analysis of protein phosphorylation by Western blot. Canonical BMP-signalling (pSmad1/5/8) as well as non-canonical (pp38, pMEK1/2 and pErk1/2) downstream BMP-signalling were investigated. A 4- and 5 -fold increased level of pSmad1/5/8 was seen in BMP-2 coated CopiOs ${ }^{\circledR}$ and BioOss ${ }^{\circledR}$, respectively, as compared to non-coated scaffolds, Fig. 2d. Phosphorylation of p38 displayed over a 2-fold increased level in BMP-2 and BMP6 coated scaffolds as compared to non-coated controls, Fig. 2e. MEK1/2 analysis displayed a 1.5- and 2.5- fold elevated phosphorylation in BMP-6 coated CopiOs ${ }^{\circledR}$ and BioOss ${ }^{\circledR}$ whereas BMP-2 and BMP-4 coated BioOss ${ }^{\circledR}$ showed 1.5- and 2.5-fold elevated levels, Fig. 2f. Erk1/2 function downstream of MEK1/2 and a 1.5-fold higher phosphorylation level was seen in both BMP-4 and BMP-6 coated BioOss $^{\circledR}$, Fig. 2g.

\section{BMP-and CaP-induced bone formation}

To investigate the in vivo performance, constructs were implanted in an ectopic nude mouse model for 5 weeks. Analysis of reconstructed 3D images from nanoCT scans displayed various tissue formation profiles by the different constructs, Fig. 3a. Upon quantification, BMP-2 and BMP6 coated scaffolds induced approximately 3 and $5 \mathrm{~mm}^{3}$ of de novo bone, respectively, Fig. 3b. Smaller volumes were induced by BMP-4 and BMP-9 coated BioOss ${ }^{\circledR}\left( \pm 1 \mathrm{~mm}^{3}\right)$. Since the size of the explants varied, the percentage of $d e$ novo formed bone was calculated, normalised to the total explant volume, Fig. 3c. The highest percentage were observed in BMP-2 coated scaffolds with 14- and $10 \%$ for $\mathrm{CopiOs}^{\circledR}$ and BioOss ${ }^{\circledR}$, respectively.

\section{Bone ossicle formation by BMP-2 and BMP-6}

Bone ossicle formation was seen in $\mathrm{CaP}$ scaffolds coated with BMP-2 and BMP-6, Fig. 4a. These ossicles contained three distinct zones where the peripheral zone displayed a cortex-like structure, a middle zone containing trabeculaelike structures and a centre zone where remnants of $\mathrm{CaP}$ granules together with trabeculae-like structures were 

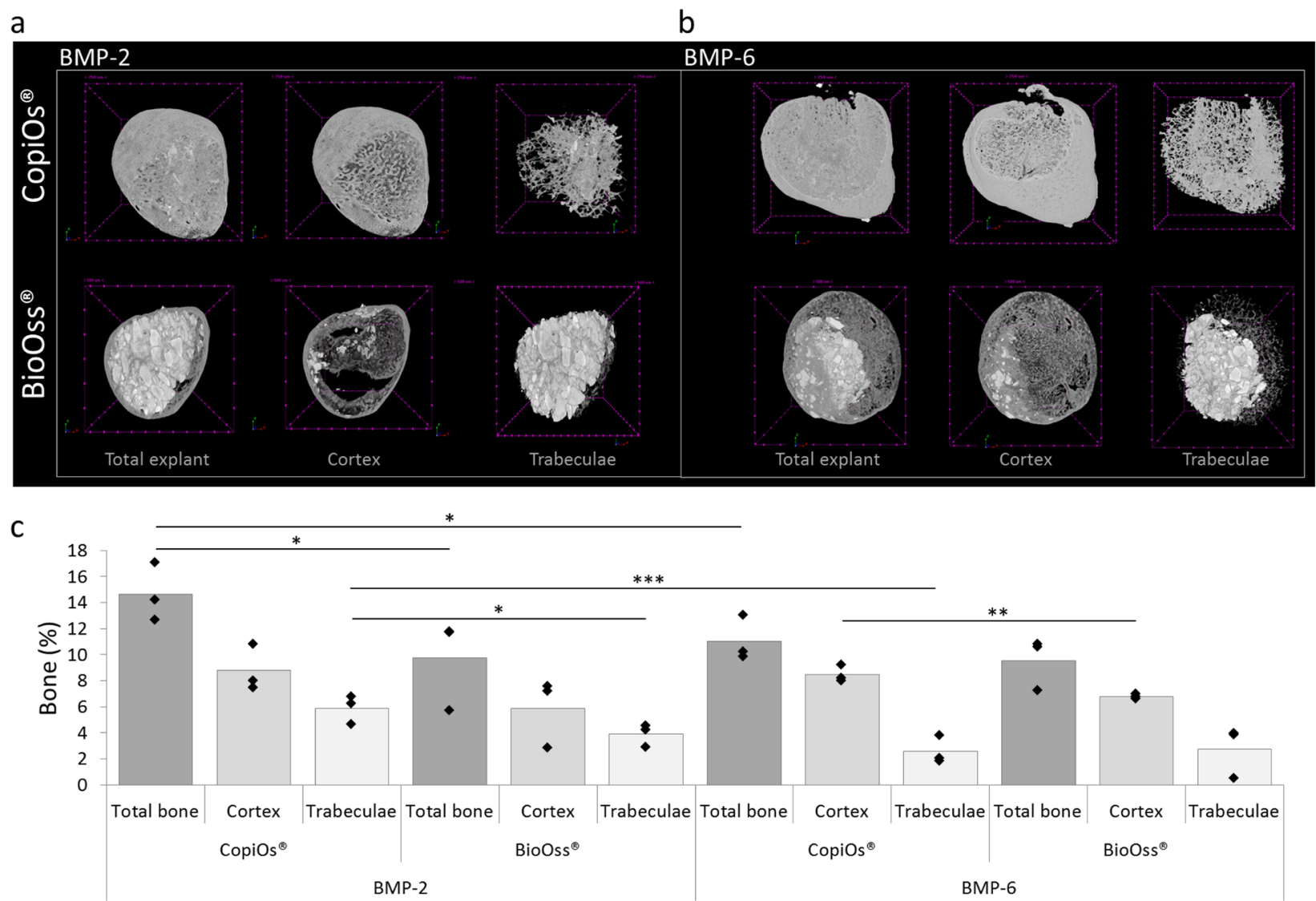

Fig. 4. Ossicle formation by BMP-2 and BMP-6. Reconstructed nanoCT-images of BMP-2 (a) and BMP-6 (b) coated $\mathrm{BiOOss}^{\circledR}$ and CopiOs ${ }^{\circledR}$ scaffolds displayed ossicle like structures with a peripheral zone containing a cortexlike bone structure, a middle zone with trabeculae-like bone structures embedded in bone marrow and a centre zone with remaining $\mathrm{CaP}$ granules and trabeculae-like bone spicules. Upon quantification, most of the percentage of total bone in all constructs came from the cortex structure (c). Statistical significance by student $t$-test, $n=4 ;{ }^{*} p<0.05$, $* * p<0.01, * * * p<0.01$.
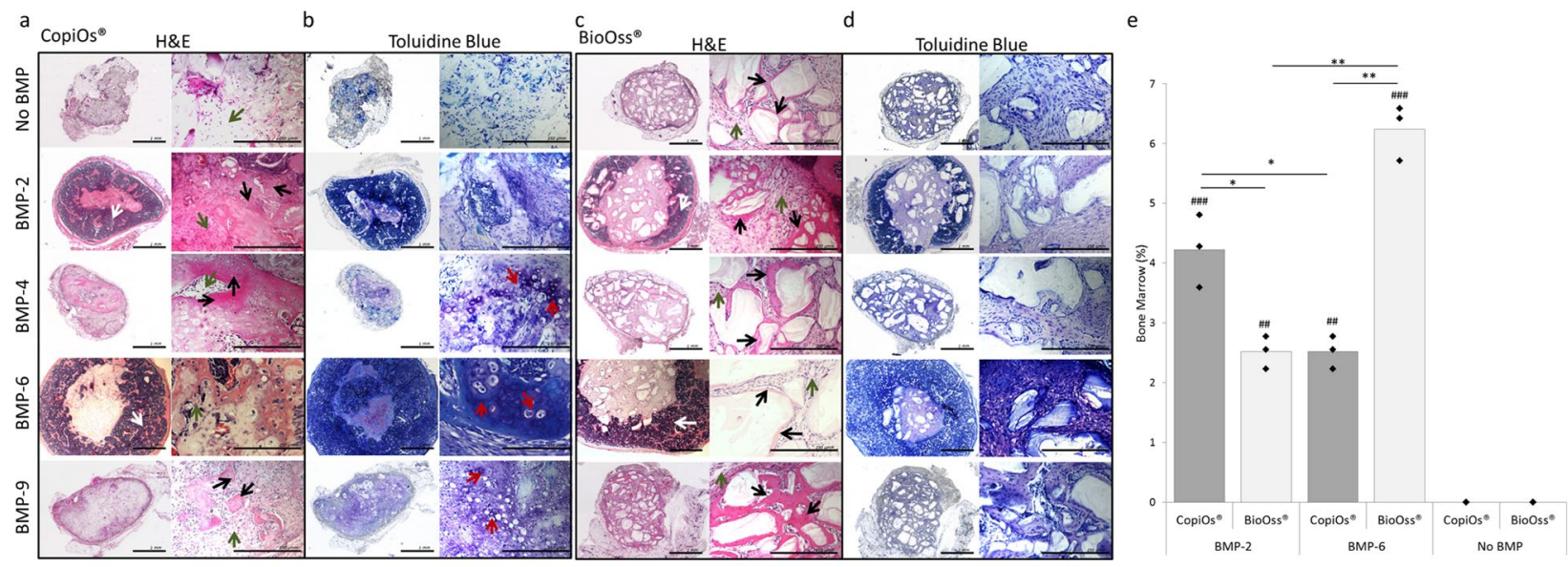

Fig. 5. Characterisation of BMP-induced bone and cartilage formation. Histological analysis of constructs harvested 5 weeks post implantation displayed varied tissue formation between the constructs. H\&E staining display bone (black arrows), bone marrow (white arrows) and fibrous tissue (green arrows) formation (CopiOs ${ }^{\circledR}:$ a, BioOss ${ }^{\circledR}:$ c). Toluidine blue staining depicts cartilage tissue with hypertrophic chondrocytes (red arrows) mainly in the central parts of the BMP-coated CopiOs ${ }^{\circledR}$ scaffolds $\left(\right.$ CopiOs $^{\circledR}:$ b and BioOss ${ }^{\circledR}: \mathbf{d}$ ). Histomorphometry of bone marrow quantification normalised to explant area (e). Statistical significance by student $t$-test, $n=4$, to: uncoated scaffolds: \#p $<0.05$, $\# \# p<0.01, \# \#$, $<0.01$, between conditions: $* p<0.05, * * p<0.01, * * * p<0.01$. 
a

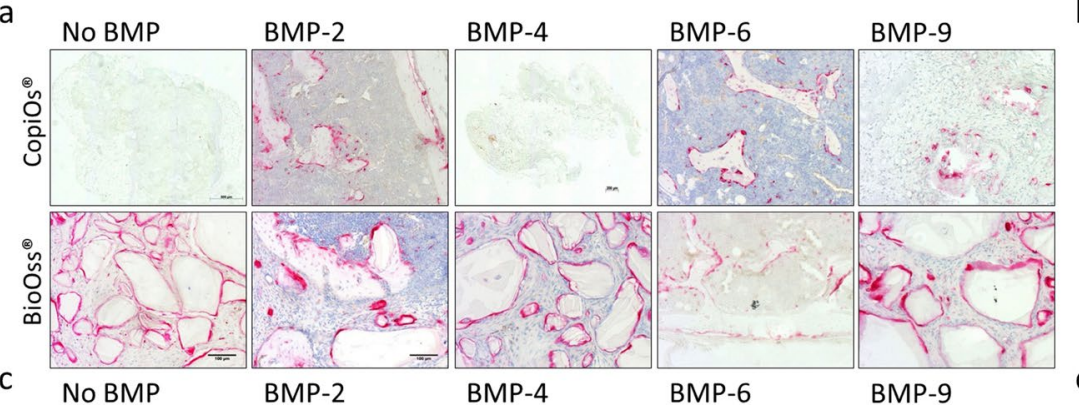

b
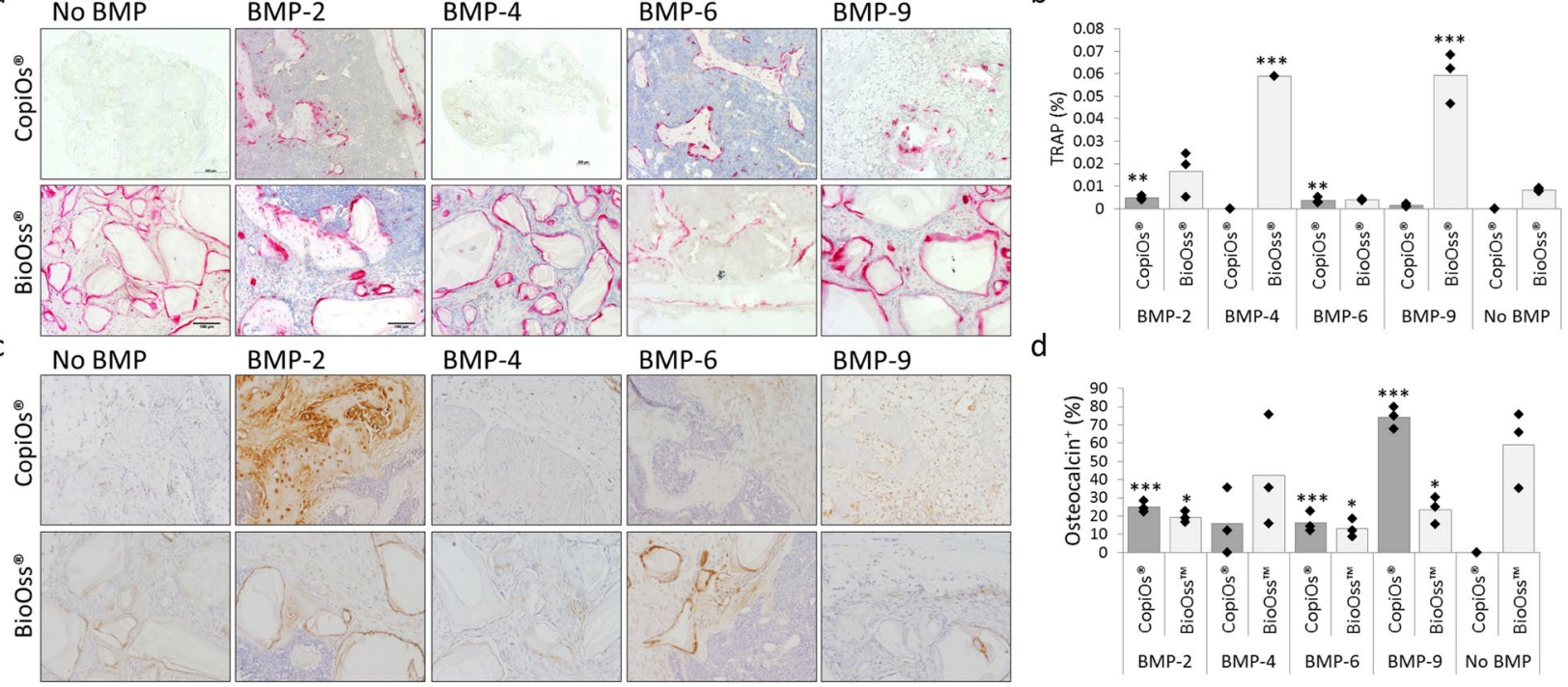

e

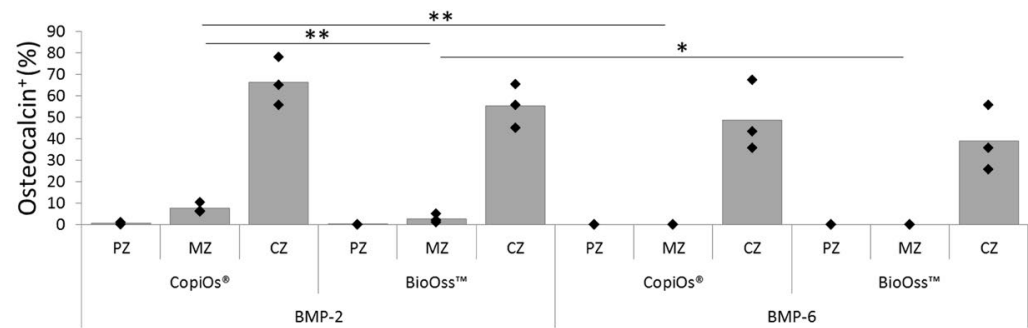

Fig. 6. Mechanism and functional analysis of BMP-induced bone formation. The newly formed bone was characterised for its function and contribution of the implanted cells. TRAP staining is a measure of osteoclast activity and remodelling and positive areas are depicted by red stain (a). Quantification of TRAP-positive area normalised to image area (b). Implanted cells contribution to the newly formed bone was investigated by IHC for human OCN, positive cell nuclei and bone matrix is depicted by brown stain (c). Quantification of OCN-positive cells (d) and in the different zones in BMP-2 and BMP-6 coated scaffolds (e), where PZ; peripheral zone, MZ; middle zone and CZ; centre zone. Statistical significance by student $t$-test, $n=4$, to: ${ }^{*} p<0.05, * * p<0.01, * * * p<0.01$.

found. To analyse the ratio of each typical structure, new regions of interest were defined. These contained the peripheral cortex-zone, the middle bone marrow zone and the centre zone containing the remaining $\mathrm{CaP}$-granules, Fig. $4 \mathrm{a}$ and $4 \mathrm{~b}$. Upon quantification, the cortex-like structure confined most of the newly formed bone in all conditions and this was further enhanced in BMP-coated CopiOs $^{\circledR}$ scaffolds as compared to BioOss ${ }^{\circledR}$, Fig. 4c.

\section{Characterisation of BMP-induced bone, cartilage and bone marrow formation}

Qualitative tissue analysis was investigated by histology and IHC. Fig. 5a and 5c display H\&E staining, which confirmed the nanoCT data, bone is indicated with black arrows. The intensity of the stain suggests the lighter areas to be less mature bone, as seen in CopiOs ${ }^{\circledR}$ scaffolds coated with BMP-4, BMP-6 and BMP-9 and more dense bone in BMP-2 coated scaffolds. Toluidine blue staining confirmed cartilage matrix in CopiOs ${ }^{\circledR}$ constructs coated with BMP$2,-4,-6$ and -9 , mainly in the central parts of the explants (indicated by red arrows), Fig. 5b and 5d. Fibrous tissue could be found in all explants (green arrows) and bone marrow was present in BMP-2 and BMP- 6 coated scaffolds in the zone between the cortex-like structure and the inner centre (white arrows), Fig. 5a and 5c. Histomorphometry showed that BMP-6 coated BioOss ${ }^{\circledR}$ and BMP-2 coated CopiOs $^{\circledR}$ gave rise to the highest percentage of bone marrow with $6 \%$ and $4 \%$ respectively, Fig. 5 e.

\section{Further characterisation of BMP/hPDC based bone formation}

In addition to bone, cartilage and bone marrow formation, the presence of osteoclasts was analysed by TRAP staining and the contribution to the newly formed bone by the implanted cells by IHC for human OCN. Areas positive for TRAP-staining were found in all samples where de novo bone was observed. TRAP-positive cells were mainly localised adjacent to the bone or surrounding the remaining CaP-granules in the BioOss ${ }^{\circledR}$ constructs, Fig. 6a. Quantification of TRAP-positive area displayed that the BioOss ${ }^{\circledR}$ explants had the highest percentage of TRAPpositive regions, Fig. 6b. Next, IHC for human OCN confirmed the contribution of implanted cells to de novo formed bone, depicted by the brown stain in cell nuclei and bone matrix in Fig. 6c. Quantification confirmed that not all cells and bone matrix stained positive, suggesting that part of the bone was host derived, Fig. 6d. In addition, BMP2 and BMP-6 samples which displayed a zonal division 


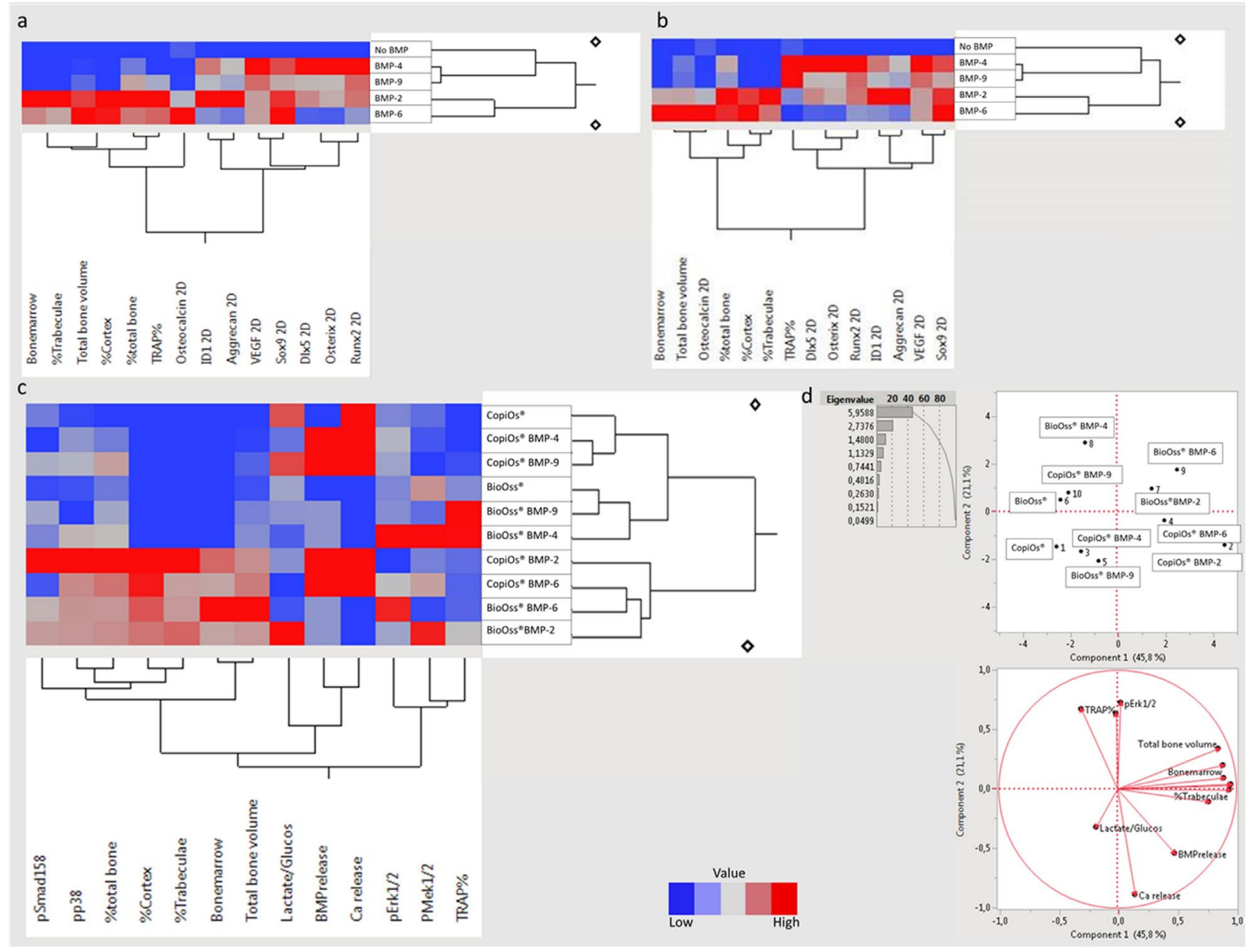

Fig. 7. Multivariate statistical analysis of the empirical data. Computational tools were used in the analysis of empirical data. Clustering of gene expression analysis in $2 \mathrm{D}$ stimulated cells with the in vivo readouts of BMP-coated CopiOs ${ }^{\circledR}$ (a) and BioOss ${ }^{\circledR}$ scaffolds (b). Clustering of 3D in vitro measurements from BMP-coated CopiOs ${ }^{\circledR}$ and BioOss ${ }^{\circledR}$ scaffolds to in vivo skeletal tissue formation (c). PCA analysis display 2 component separating factors related to in vivo bone formation (Component 1) and $\mathrm{Ca}^{2+}$-BMP interaction (Component 2) (d).

containing an peripheral cortex-like zone (PZ), a middle bone marrow zone (MZ) and a centre zone (CZ) containing remaining CaP-granules, displayed a clear difference in contribution, Fig. 6e. The PZ was mainly host-derived, some positive staining was detected in the MZ of the BMP2 coated-CopiOs ${ }^{\circledR}$, whereas both scaffold types displayed positivity within the bone in the $\mathrm{CZ}$.

Multivariate statistical analysis of the empirical data A drawback in a large set of empirical data, with several factors known to play critical roles in the experimental outcome, is the lack of understanding their contribution and importance. Therefore, we applied multivariate statistical analysis as a tool to investigate the weighted value of the introduced factors. Hierarchical clustering allows identifying similarities between experimental conditions across the data set. The closer the resemblance in measurement profile between two conditions, the closer they will be clustered together. Two-way clustering bundles the experimental conditions based on the measurement profile and show which of the measurements have similar profiles across the experimental conditions. Hierarchical clustering of in vitro $2 \mathrm{D}$ stimulation measurements and the in vivo bone formation displayed clustering of $O C N$ expression in 2D stimulated cells and in vivo formed bone, bone marrow and bone remodelling for CopiOs ${ }^{\circledR}$ and BioOss ${ }^{\circledR}$, Fig. 7a and $7 \mathrm{~b}$ respectively. In addition, in BMP-2 coated CopiOs ${ }^{\circledR}$, clustering of elevated expression of chondrogenic marker $A C A N$ and $I D 1$ was found. Readouts on BMP-pathway activation in 3D and in vivo tissue formation displayed clustering of total bone volume and bone marrow formation, trabeculae and cortex formation, $\%$ total bone with phosphorylation of Smad1/5/8 and p38, Fig. 7c. Moreover, grouping between $\mathrm{Ca}^{2+}$ - and BMP-2-release from the scaffold was depicted while TRAP-positivity was clustered with phosphorylation of MEK1/2 and Erk1/2. Cluster analysis of the different combinations of BMP-ligand and $\mathrm{CaP}$ scaffold displayed grouping of non-coated CopiOs ${ }^{\circledR}$ to BMP-4 and BMP-9coated scaffold. A similar phenomenon was seen for the BioOss ${ }^{\circledR}$ scaffold, showing a dominant stimulatory role of the biomaterial over BMP-ligand in these constructs. 
In contrast, BMP- 6 coated $\mathrm{CaP}$ scaffolds are clustered, demonstrating a dominant role for BMP-6 over the biomaterial. Interestingly, BMP-2 coated biomaterials were clustered next to the same BMP-6 coated one, presenting BMP-2 to be less dominant over the biomaterial than BMP-6, but more so than BMP-4 and BMP-9. Principal component analysis allows the visualisation of the maximum amount of information that is present within the entire dataset. A principal component represents the information contained within the data by choosing linear combinations of the measurements in such a way that the first principal component accounts for as much as possible for the variance available in the data set. The second component is chosen in the same way under the added constraint of being uncorrelated to the first component. Upon analysis, two clear components separating the different conditions as well as biological readouts related to in vivo bone (Component 1 ) and $\mathrm{Ca}^{2+}$-BMP-interaction (Component 2), Fig. 7d.

\section{Discussion}

Well characterised cell based ATMPs have recently come to attention to replace standard treatment options for non-healing long bone fractures. Current advances in the development of biologically functional bone grafts further improve our knowledge regarding the early phases of bone regeneration, enabling clinically relevant development of functional constructs. Previous reports displayed that $\mathrm{Ca}^{2+}$-induced bone formation by hPDCs is a process that requires activation of BMP and Wnt signalling (Eyckmans et al., 2010). Encouragingly, bone formation in these constructs is a biomimetic process, where progenitor cell condensation, bone marrow and bone formation can be detected, a suggested requirement for a successful clinical outcome (Lenas et al., 2009a; Lenas et al., 2009b; Roberts et al., 2011). However, the process is slow and limited amounts of skeletal tissue are developed. Subsequently, we hypothesised that we could further improve these constructs' bone forming capacity by coating the scaffolds with recombinant BMP-ligands. By including these potent factors in a cell based-strategy, more physiological levels of BMPs could be used, hence overcoming current impediments while reaching a satisfactory outcome with clinical translation in mind.

Initially, in vitro expanded hPDCs were characterised and confirmed positive for MSC markers and for expressing the BMP type 1 and type 2 receptors. This was encouraging, since it has been reported that in vitro $2 \mathrm{D}$ culture and expansion of mesenchymal progenitor cells reduce MSC characteristics as well as responsiveness to stimulation (Bara et al., 2014). Subsequently, BMPs known to bind to these receptors, with previously reported osteochondrogenic properties, were selected. BMP-2, BMP-4, BMP-6 and BMP-9 enhanced chondrogenic as well as osteogenic differentiation which could be correlated to elevated BMP-signalling. The dual osteo- and chondrogenic differentiation profiles may be explained by the heterogeneous pool of progenitor cells and fibroblasts hPDCs represent (Roberts et al., 2015). Potentially, depending on the progenitor cell's spatial location in the periosteal layer, cells may be primed for a specific differentiation pathway. Neither BMP-7 nor GDF5 induced differentiation in the present setting. Since previous reports confirm both factors having osteo-chondrogenic potency in vitro and/or in vivo, this was an unexpected finding and may be due to the experimental setup and/or species specificity (Eyckmans and Luyten, 2006; Gruber et al., 2001).

Potent BMPs were then coated onto clinically approved CaP-scaffolds followed by cell seeding. After $24 \mathrm{~h}$, neither BMP-9 nor BMP-4 coated CopiOs ${ }^{\circledR}$ displayed enhanced phosphorylation in any of the markers of the investigated pathways, even though 2D stimulation enhanced both osteo- and chondrogenic differentiation. Possibly, the CaP-environment interferes with the activated BMPsignalling, since CaP-stimulation of hPDCs can lead to cell proliferation and osteogenic differentiation, further supported by the metabolic analysis (Agathocleous and Harris, 2013; Chai et al., 2014). BMP signalling pathways are strictly regulated by cross-talks and feedbackloops, controlled by co-factors and inhibitors resulting in a controlled bone forming process upon accurate pathway activation (Groppe et al., 2002; Zhang et al., 2013). Therefore, inappropriate $\mathrm{Ca}^{2+}$-stimulation may inhibit activated signalling by the coated BMP-ligand. Consequently, CaP-scaffolds may function synergistically with specific BMP-ligands while in an inhibitory fashion with others. Alternatively, protein phosphorylation can take place within an hour or even minutes after stimulation has started and can fluctuate due to events involved during phosphorylation, such as receptor-ligand complex internalisation and recycling (Goldberg et al., 2002). Therefore, phosphorylation events might not be reflected in the selected time point but still take place, even though the use of pooled cells minimises the risk. Nevertheless, the time point chosen, $24 \mathrm{~h}$ post cell seeding reflects the final in vitro stage of the construct prior to implantation, providing important information of the implanted construct, at the time of implantation.

Upon in vivo implantation, all constructs coated with BMPs induced bone. However, BMP-2 and BMP-6 coated scaffolds induced the highest amount and gave rise to bone-organ organisation (Scotti et al., 2013). Interestingly, the peripheral cortex was formed mainly by host cells. Possibly, this could be an effect of BMP-diffusion from the scaffold, supported by the BMP-2 release. The diffusion may attract and stimulate host cells to form the peripheral cortex like structure during a fast process, leading to the more mature bone (Wildemann et al., 2011). The bone formed in the centre zone is to a larger extent formed by implanted cells and especially in the CopiOs ${ }^{\circledR}$ constructs, displayed as less mature. This proposes that the combined action of BMP- and CaP-stimulation of hPDCs results in a slower bone forming process following the endochondral pathway.

Due to the large and complex set of empirical data, multivariate statistical methods were used to gain further insight into the effects of stimulatory factors in the experimental design. Interestingly, clustering was found between total bone, percentage of: bone marrow, trabeculae, cortex and total bone to elevated phosphorylation levels 
of Smad1/5/8 and p38. This suggests the importance of their activation in $\mathrm{BMP} / \mathrm{CaP}$ induced bone formation as the major activated pathways during cell differentiation. Another cluster was found for BMP- and $\mathrm{Ca}^{2+}$-release, suggesting elevated $\mathrm{Ca}^{2+}$-release to cause a decrease in $\mathrm{pH}$, providing a more soluble environment for the BMP (Hillger et al., 2005; Kamp et al., 1998). Alternatively, the release of $\mathrm{Ca}^{2+}$ may mediate the subsequent release and biological availability of BMPs bound to the CaP-granules through hydrogen/ionic/electrostatic/hydrophobic interactions (Wang et al., 2013).

TRAP staining, an indicator of osteoclast activity, was computationally related to elevated phosphorylation levels of the MAPK-pathway MEK1/2 - Erk1/2. This pathway was previously reported essential in blood vessel recruitment (Nakatsu et al., 2003), proposing this pathway being important in remodelling of these constructs. Moreover, a scaffold-specific clustering of in vivo bone tissue formation to BMP-induced 2D differentiation was seen. Tissue formation in BMP-coated $\mathrm{CopiOs}^{\circledR}$ was statistically related to elevated expression of chondrogenic-, osteogenic- as well as activated BMPsignalling markers. BioOss ${ }^{\circledR}$ constructs on the other hand, where no cartilage remnants were found, was also not clustered to chondrogenic markers. This suggests that the CopiOs $^{\circledR}$ scaffold may provide a more suitable environment for induction of endochondral bone formation, due to the specific CaP-environment provided. This is of relevance for clinical translation, since fracture healing through a cartilage intermediate will reach stability faster, essential for successful healing.

Lastly, the cluster analysis provided information of the weighted value of specific BMP-ligands and the CaPscaffold characteristics, with regard to the in vitro activated pathways as well as to the in vivo outcome. Both BMP-4 and BMP-9 coated scaffolds were clustered to uncoated, suggesting the scaffold characteristics to be dominant over BMP-4 and BMP-9 ligands. On the other hand, analysis of BMP- 6 coated CaP-scaffolds suggests BMP-6 to overrule the stimulatory effect of the CaP-materials. Interestingly, BioOss ${ }^{\circledR}$ scaffolds coated with BMP-2 was clustered to BMP-6 coated BioOss ${ }^{\circledR}$ followed by BMP-2 coated CopiOs ${ }^{\circledR}$. These data suggest that BMP-2 interacts with the CaP-material to a higher extent than BMP-6 on stimulation of hPDCs, further supported by the PCA analysis. This is further reflected by the varied contribution to in vivo bone formation by cells seeded on the two CaP scaffolds. Possibly, the BMP and CaP-material interaction with subsequent in vivo tissue formation could be due to differently activated downstream signalling mechanisms which are regulated by the expression profile of BMPreceptors by hPDCs.

It has been reported that BMP-2 binds preferentially and predominantly to ALK3 whereas BMP-6 primarily binds to ALK2 (Ebisawa et al., 1999; ten Dijke et al., 1994). On gene expression level, ALK2 expression was detected in hPDCs, however we failed to confirm this on the protein level. Even though activated BMP-6 signalling may occur by binding to other receptors, this could cause the less impressive contribution of the implanted/ donor cells in BMP-6 constructs. Subsequently, unbound BMPligand released from the coated scaffold or secreted by the stimulated cells leads to recruitment of cells, when available, from the host environment. This is of relevance as fast and proper incorporation into the host tissue is essential for the clinical outcome.

Before clinical translation, further studies regarding the concentration of BMP-ligands, additional time points and cells isolated from individual donors are required. Nevertheless, these data provide important insights in the combined effect of BMP- and CaP-induced bone formation for skeletal regenerative medicine.

\section{Conclusion}

In this study, we have combined the stimulatory effects of BMPs and 3D CaP-scaffolds into cell-based ATMPs for bone tissue engineering. Different bone forming capacities of the constructs were observed depending on the specific combination of BMP-ligand and CaPscaffold. The synergistic effect of these two factors leads to functional skeletal tissue formation including a cartilage intermediate, bone as well as bone marrow formation and tissue remodelling. This study presents further evidence for the potential of ligands from the BMP family in the development of cell-based constructs for bone regenerative strategies.

\section{Acknowledgements}

This work is part of Prometheus, the KU Leuven R\&D division for skeletal tissue engineering. http://www. kuleuven.be/prometheus. The authors would like to acknowledge Dr. Dennis Lambrechts for developing the MatLab image analysis tool, Dr. Greet Kerckhofs for assistance in the nanoCT scanning and analysis. The research leading to these results has been funded by the government agency for Innovation by Science and Technology (IWT-SBO-111545), the Research FoundationFlanders (FWO: $12 \mathrm{G} 2715 \mathrm{~N}$ - Med 5 and 1.5.172.13N Interdisc, respectively.), European Research Council under the European Union's Seventh Framework Programme (FP/2007-2013) / ERC Grant Agreements n. 279100 and 249191; from the Research Programme of the Research Foundation - Flanders (FWO), grant n. G.0982.11 and from the special research fund of the KU Leuven (GOA/13/016). The nanoCT images have been generated on the X-ray computed tomography facilities of the Department of Materials Engineering of the KU Leuven, financed by the Hercules Foundation (project AKUL 09/001: Micro- and nanoCT for the hierarchical analysis of materials).

\section{References}

Agathocleous M, Harris WA (2013) Metabolism in physiological cell proliferation and differentiation. Trends Cell Biol 23: 484-492. 
Ai-Aql ZS, Alagl AS, Graves DT, Gerstenfeld LC, Einhorn TA (2008) Molecular mechanisms controlling bone formation during fracture healing and distraction osteogenesis. J Dent Res 87: 107-118.

Bara JJ, Richards RG, Alini M, Stoddart MJ (2014) Concise review: Bone marrow-derived mesenchymal stem cells change phenotype following in vitro culture: implications for basic research and the clinic. Stem Cells 32: 1713-1723.

Barnes GL, Kostenuik PJ, Gerstenfeld LC, Einhorn TA (1999) Growth factor regulation of fracture repair. J Bone Miner Res 14: 1805-1815.

Betz RR (2002) Limitations of autograft and allograft: new synthetic solutions. Orthopedics 25: s561-570.

Chai YC, Geris L, Bolander J, Pyka G, Van Bael S, Luyten FP, Schrooten J (2014) In vivo ectopic bone formation by devitalized mineralized stem cell carriers produced under mineralizing culture condition. Biores Open Access 3: 265-277.

Cho TJ, Gerstenfeld LC, Einhorn TA (2002) Differential temporal expression of members of the transforming growth factor beta superfamily during murine fracture healing. J Bone Miner Res 17: 513-520.

Colnot C (2009) Skeletal cell fate decisions within periosteum and bone marrow during bone regeneration. $\mathrm{J}$ Bone Miner Res 24: 274-282.

De Bari C, Dell'Accio F, Luyten FP (2001) Human periosteum-derived cells maintain phenotypic stability and chondrogenic potential throughout expansion regardless of donor age. Arthritis Rheum 44: 85-95.

De Bari C, Dell'Accio F, Vanlauwe J, Eyckmans J, Khan IM, Archer CW, Jones EA, McGonagle D, Mitsiadis TA, Pitzalis C, Luyten FP (2006) Mesenchymal multipotency of adult human periosteal cells demonstrated by single-cell lineage analysis. Arthritis Rheum 54: 1209-1221.

Ebisawa T, Tada K, Kitajima I, Tojo K, Sampath TK, Kawabata M, Miyazono K, Imamura T (1999) Characterization of bone morphogenetic protein-6 signaling pathways in osteoblast differentiation. J Cell Sci 112: 3519-3527.

Eyckmans J, Luyten FP (2006) Species specificity of ectopic bone formation using periosteum-derived mesenchymal progenitor cells. Tissue Eng 12: 2203-2213.

Eyckmans J, Roberts SJ, Schrooten J, Luyten FP (2010) A clinically relevant model of osteoinduction: a process requiring calcium phosphate and BMP/Wnt signalling. J Cell Mol Med 14: 1845-1856.

Fong K, Truong V, Foote CJ, Petrisor B, Williams D, Ristevski B, Sprague S, Bhandari M (2013) Predictors of nonunion and reoperation in patients with fractures of the tibia: an observational study. BMC Musculoskelet Disord 14: 103.

Gilboa L, Nohe A, Geissendorfer T, Sebald W, Henis YI, Knaus P (2000) Bone morphogenetic protein receptor complexes on the surface of live cells: a new oligomerization mode for serine/threonine kinase receptors. Mol Biol Cell 11: 1023-1035.

Glassman SD, Carreon L, Djurasovic M, Campbell MJ, Puno RM, Johnson JR, Dimar JR (2007) Posterolateral lumbar spine fusion with INFUSE bone graft. Spine J 7: 44-49.
Goldberg PL, MacNaughton DE, Clements RT, Minnear FL, Vincent PA (2002) p38 MAPK activation by TGF-beta1 increases MLC phosphorylation and endothelial monolayer permeability. Am J Physiol Lung Cell Mol Physiol 282: L146-154.

Graham SJ, Wicher KB, Jedrusik A, Guo G, Herath W, Robson P, Zernicka-Goetz M (2014) BMP signalling regulates the pre-implantation development of extraembryonic cell lineages in the mouse embryo. Nat Commun 5: 5667.

Groppe J, Greenwald J, Wiater E, Rodriguez-Leon J, Economides AN, Kwiatkowski W, Affolter M, Vale WW, Izpisua Belmonte JC, Choe S (2002) Structural basis of BMP signalling inhibition by the cystine knot protein Noggin. Nature 420: 636-642.

Gruber R, Mayer C, Bobacz K, Krauth MT, Graninger W, Luyten FP, Erlacher L (2001) Effects of cartilagederived morphogenetic proteins and osteogenic protein-1 on osteochondrogenic differentiation of periosteumderived cells. Endocrinology 142: 2087-2094.

Hartung A, Bitton-Worms K, Rechtman MM, Wenzel V, Boergermann JH, Hassel S, Henis YI, Knaus P (2006) Different routes of bone morphogenic protein (BMP) receptor endocytosis influence BMP signaling. Mol Cell Biol 26: 7791-7805.

Hillger F, Herr G, Rudolph R, Schwarz E (2005) Biophysical comparison of BMP-2, ProBMP-2, and the free pro-peptide reveals stabilization of the pro-peptide by the mature growth factor. J Biol Chem 280: 14974-14980.

Kamp F, Donoso P, Hidalgo C (1998) Changes in luminal $\mathrm{pH}$ caused by calcium release in sarcoplasmic reticulum vesicles. Biophys J 74: 290-296.

Kerckhofs G, Sainz J, Wevers M, Van de Putte T, Schrooten J (2013) Contrast-enhanced nanofocus computed tomography images the cartilage subtissue architecture in three dimensions. Eur Cell Mater 25: 179189.

Langer R, Vacanti JP (1993) Tissue engineering. Science 260: 920-926.

Lenas P, Moos M, Luyten FP (2009a) Developmental engineering: a new paradigm for the design and manufacturing of cell-based products. Part I: from three-dimensional cell growth to biomimetics of in vivo development. Tissue Eng Part B Rev 15: 381-394.

Lenas P, Moos M, Luyten FP (2009b) Developmental engineering: a new paradigm for the design and manufacturing of cell-based products. Part II: from genes to networks: tissue engineering from the viewpoint of systems biology and network science. Tissue Eng Part B Rev 15: 395-422.

Ma J, Both SK, Yang F, Cui FZ, Pan J, Meijer GJ, Jansen JA, van den Beucken JJ (2014) Concise review: cell-based strategies in bone tissue engineering and regenerative medicine. Stem Cells Transl Med 3: 98-107.

Nakatsu MN, Sainson RC, Perez-del-Pulgar S, Aoto JN, Aitkenhead M, Taylor KL, Carpenter PM, Hughes CC (2003) VEGF(121) and VEGF(165) regulate blood vessel diameter through vascular endothelial growth factor receptor 2 in an in vitro angiogenesis model. Lab Invest 83: $1873-1885$. 
Nohe A, Hassel S, Ehrlich M, Neubauer F, Sebald W, Henis YI, Knaus P (2002) The mode of bone morphogenetic protein (BMP) receptor oligomerization determines different BMP-2 signaling pathways. J Biol Chem 277: 5330-5338.

Pobloth AM, Duda GN, Giesecke MT, Dienelt A, Schwabe P (2015) High-dose recombinant human bone morphogenetic protein-2 impacts histological and biomechanical properties of a cervical spine fusion segment: results from a sheep model. J Tissue Eng Regen Med doi: 10.1002/term.2049

Roberts SJ, Geris L, Kerckhofs G, Desmet E, Schrooten J, Luyten FP (2011) The combined bone forming capacity of human periosteal derived cells and calcium phosphates. Biomaterials 32: 4393-4405.

Roberts SJ, van Gastel N, Carmeliet G, Luyten FP (2015) Uncovering the periosteum for skeletal regeneration: the stem cell that lies beneath. Bone 70: 1018.

Scotti C, Piccinini E, Takizawa H, Todorov A, Bourgine P, Papadimitropoulos A, Barbero A, Manz MG, Martin I (2013) Engineering of a functional bone organ through endochondral ossification. Proc Natl Acad Sci U S A 110: 3997-4002.

Shimasaki S, Moore RK, Otsuka F, Erickson GF (2004) The bone morphogenetic protein system in mammalian reproduction. Endocr Rev 25: 72-101.

ten Dijke P, Yamashita H, Sampath TK, Reddi AH, Estevez M, Riddle DL, Ichijo H, Heldin CH, Miyazono K (1994) Identification of type I receptors for osteogenic protein-1 and bone morphogenetic protein-4. J Biol Chem 269: 16985-16988.

Tiedemann H, Asashima M, Grunz H, Knochel W (2001) Pluripotent cells (stem cells) and their determination and differentiation in early vertebrate embryogenesis. Dev Growth Differ 43: 469-502.

Varga AC, Wrana JL (2005) The disparate role of BMP in stem cell biology. Oncogene 24: 5713-5721.

Wang J, Zhang H, Zhu X, Fan H, Fan Y, Zhang X (2013) Dynamic competitive adsorption of bone-related proteins on calcium phosphate ceramic particles with different phase composition and microstructure. J Biomed Mater Res B Appl Biomater 101: 1069-1077.

White AP, Vaccaro AR, Hall JA, Whang PG, Friel BC, McKee MD (2007) Clinical applications of BMP-7/OP-1 in fractures, nonunions and spinal fusion. Int Orthop 31: 735-741.

Wildemann B, Lange K, Strobel C, Fassbender M, Willie B, Schmidmaier G (2011) Local BMP-2 application can rescue the delayed osteotomy healing in a rat model. Injury 42: 746-752.

Wu MY, Hill CS (2009) Tgf-beta superfamily signaling in embryonic development and homeostasis. Dev Cell 16: 329-343.

Yu YY, Lieu S, Lu C, Miclau T, Marcucio RS, Colnot C (2010) Immunolocalization of BMPs, BMP antagonists, receptors, and effectors during fracture repair. Bone 46: 841-851.

Zhang R, Oyajobi BO, Harris SE, Chen D, Tsao C, Deng HW, Zhao M (2013) Wnt/beta-catenin signaling activates bone morphogenetic protein 2 expression in osteoblasts. Bone 52: 145-156.

\section{Discussion with Reviewers}

R. Vicki: How do you envision using the information gained from multivariate analyses to design tissueengineering strategies?

Authors: One of the hurdles in understanding and evaluating the effect of stimulatory factors in a 3D system is the complexity and the potential size of the experimental dataset. To deal with these hurdles, multivariate analysis is an efficient methodology to identify positive and/or negative factors in the system. Furthermore, the use of computational evaluation of the empirical data is a possible means to gain in-depth knowledge on cell-biomaterial interactions in a cost- and time-effective manner. We intend to use this information in various ways. Information on what measurements are most predictive for this outcome will allow us to further investigate these pathways or these material characteristics. This will then serve as a starting point for more mechanistic experimental and/or modelling studies that will ultimately lead to improved tissue engineering designs and strategies.

R. Vicki: Do you believe the results are highly related to the use of hPDC, or would they be generalisable for other hMSC?

Authors: Periosteum derived cells represent a unique source of osteo-chondroprogenitor cells, shown crucial for successful fracture repair. In comparison to other MSCs such as bone marrow stromal cells or adipocytederived stem cells, differences in cell morphology as well as proliferation and differentiation capacity have been reported. Therefore, the response demonstrated in the presented manuscript by hPDCs should not be seen as general for other MSCs. Nevertheless, a similar approach would be of interest in order to develop promising ATMPs based on alternative cell populations.

D. James: How much of a contribution to bone formation can be attributed to host versus donor cells?

Authors: Contribution of implanted cells to the newly formed bone was investigated by immunohistochemistry for human specific osteocalcin. About $20 \%$ of the cells entrapped or lining the newly formed bone displayed positive staining in constructs containing BMPs. However, this can be seen as an underestimation, since bone forming cells of human origin, depending on the differentiation state, may or may not be positive for osteocalcin.

D. James: Are there underlying differences in the crystalline structures of BioOss ${ }^{\circledR}$ and $\mathrm{CopiOs}^{\circledR}$ that accounts for the differences in BMP interactions and release characteristics?

Authors: The crystalline structures of BioOss ${ }^{\circledR}$ versus $\mathrm{CopiOs}^{\circledR}$ are indeed different. CaP-granules in BioOss ${ }^{\circledR}$ are derived from bovine bone (hydroxyapatite) with a highly crystalline structure. In contrast, those present in CopiOs ${ }^{\circledR}$ 
are synthetic dicalcium phosphate $\left(\mathrm{CaHPO}_{4}\right)$. This firstly causes a different interaction between the BMP ligand and the two scaffolds. Secondly, the highly crystallised CaPgranules in $\mathrm{BioOss}^{\circledR}$ are fairly stable and dissolve slowly whereas the amorphous $\mathrm{CaHPO}_{4}$ in $\mathrm{CopiOs}^{\circledR}$ dissolves relatively fast. Consequently, the release kinetics of
BMP-ligands are affected due to the difference in material degradation attributed to the different crystalline structures.

Editor's Note: Scientific Editor in charge of the paper: Joost de Bruijn. 